\title{
Construindo saberes nas redes sociais
}

\author{
Aline Bairros Soares - PPGEPT/UFSM, aline.qmc.bs@ gmail.com \\ Sandra Palma Botega - PPGTER/UFSM, sandrabotega@ gmail.com \\ Leila Maria Araújo dos Santos - PPGEPT/UFSM, leilamas@ gmail.com \\ Ricardo Machado Ellensohn - PPGEPT/UFSM, ricardoellensohn@ gmail.com \\ Claudia Smaniotto Barin, - PPGEPT/UFSM, claudiabarin@nte.ufsm.br
}

\begin{abstract}
Resumo: Imersos num mundo tecnológico, os jovens vêm desenvolvendo novas formas de aprender por meio do compartilhamento de saberes e questionamentos com seus pares nos ambientes virtuais oriundos das ferramentas da web 2.0. Nesse sentido o presente trabalho visa avaliar o uso das redes sociais como um espaço de compartilhamento e aprendizagem no ensino superior. $\mathrm{O}$ estudo consiste num relato de experiência do uso e produção de recursos educacionais digitais compartilhados no Facebook ${ }^{\circledR}$ com estudantes $^{\circ}$ de Agronomia ingressantes à universidade nos anos de 2015 a 2017. Os resultados apontam que, apesar das redes sociais requererem do professor uma nova postura no que tange ao planejamento, compartilhamento e monitoramento, o Facebook aproxima os agentes do processo de aprendizagem à medida que provê maior liberdade de expressão, o que resulta em maior participação dos estudantes e consequentemente na construção do conhecimento na coletividade.
\end{abstract}

Palavras-chave: mídia social. Ensino de Química. Web 2.0.

\section{Building knowledge in the social network}

ABSTRACT: Immersed in a technological world, young people have been developing new ways of learning by sharing knowledge and questioning with their peers in virtual environments from web 2.0 tools. In this sense, the present work aims to evaluate the use of social networks as a space of sharing and learning in higher education. The study consists of an experience report on the use and production of digital educational resources shared on Facebook ${ }^{\circledR}$ with Agronomy students entering the university in the years 2015 to 2017. The results point out that, although social networks require the teacher a new attitude regarding planning, sharing and monitoring, the Facebook brings the agents of the learning process closer together as it provides greater freedom of expression, which results in greater student participation and consequently in the construction of knowledge in the collective.

Keywords: Social media. Chemistry teaching. Web 2.0.

\section{Introdução}

A evolução tecnológica vem rompendo paradigmas e modificando a forma como o ser humano se relaciona com o ambiente nas diversas áreas, desde o mundo do trabalho, as relações humanas e, porque não dizer, a aquisição do conhecimento. A onipresença dos recursos das tecnologias digitais da informação e da comunicação (TDIC) está cada vez mais arraigada nos nossos hábitos cotidianos modificando a forma como interagimos e nos informamos.

Nesse sentido, as redes sociais vêm ganhando espaço, principalmente entre o público jovem, denominados por Da Silva e Pinto (2009) como geração C, que não se restringe apenas a uma faixa etárias, mas é caracterizada por indivíduos imersos no 
mundo virtual, quer nos jogos online ou nas redes sociais. Essas redes são utilizadas não apenas para o viés social, mas cada vez mais, para o compartilhamento de experiências e questionamentos, despertando o interesse de profissionais da educação sobre as potencialidades e desafios de seu uso no contexto educativo (PATRÍCIO, GONÇALVES, 2010; TÚÑEZ LÓPEZ, GARCIA, 2012).

O Facebook ${ }^{\circledR}$ tem lugar de destaque nos trabalhos relacionados ao uso das redes sociais na perspectiva do ensino e aprendizagem, sendo uma plataforma popular que possibilita a comunicação online e pode mediar o processo de construção de saberes à medida que os estudantes compartilham e discutem os problemas encontrados no cotidiano escolar (BOSCH 2009; RATCHAN, FIRPO, 2001; RACTHAM; FIRPO, 2011; IRWIN et al, 2012; ELLENSOHN, BARIN, 2016).

Como afirma Da Silva e Pinto (2009), os jovens dessa nova geração já nascem rodeados de tecnologias, compreendendo o mundo sob uma outra perspectiva. Nesse sentido, as aulas presenciais meramente expositivas mediadas pelo uso do data show ou da lousa, são normalmente desinteressantes para estes indivíduos, visto que as mesmas não contemplam tudo o que estes experimentam no mundo digital. Assim, surge a questão de pesquisa: podem as redes sociais contribuir para o aprendizado de estudantes universitários?

Nesse contexto, o presente trabalho visa avaliar o uso da rede social como um ambiente de construção de saberes no ensino superior.

\section{Metodologia}

O trabalho consiste num estudo descritivo qualitativo de cunho crítico-reflexivo acerca de um relato de experiência, a partir de uma prática já existente na disciplina de Química para a Agronomia, desde 2015. De acordo com Gil (2010), o relato de experiência da margem para o pesquisador relatar suas experiências e vivências associando-as com o saber científico.

Foram sujeitos da pesquisa 322 estudantes de 5 turmas de ingressantes do Curso de Agronomia no contexto da disciplina Química Agronomia de uma Universidade Federal no período de 2015 a 2017. Para cada uma das turmas foi criado um grupo fechado, no qual apenas os integrantes possuem acesso às informações, discussões e compartilhamentos. Assim, os dados utilizados neste relato de experiência foram coletados ao longo de 5 semestres letivos utilizando a rede social Facebook ${ }^{\circledR}$ (discussões, $^{2}$ comentários, enquetes e produções). Além da coleta de dados na rede social, utilizou-se o diário de bordo da professora e monitoras da disciplina no decorrer das aulas presenciais (teóricas e práticas) no período.

A disciplina é ofertada pelo Departamento de Química, na modalidade presencial, sendo que $50 \%$ da disciplina é destinada às aulas práticas e $50 \%$ às aulas teóricas. Após as aulas presenciais, eram disponibilizados na rede social materiais complementares, como apresentações do PowerPoint, desenvolvidas para ilustrar as aulas teóricas, assim como histórias em quadrinhos e recursos digitais, produzidos pelas autoras. No intuito de flexibilizar e potencializar a aprendizagem eram minuciosamente avaliados, selecionados e disponibilizados recursos educacionais multimídia, como por exemplo, animações e simulações.

Por outro lado, os estudantes deviam participar dessa construção coletiva de saberes provendo materiais digitais que compartilhados na rede. Os resultados obtidos no decorrer do estudo são apresentados e problematizados a seguir.

\section{Resultados e Discussão}


As turmas de química para a Agronomia possuem aproximadamente 60 estudantes a cada semestre, sendo que a mesma é ofertada no primeiro semestre da grade curricular do curso, ou seja, é composta na sua maioria por estudantes ingressantes no ensino superior. Mais de $70 \%$ dos estudantes tem idade inferior a 20 anos e faz uso diário das tecnologias digitais da informação e da comunicação. Dentre os principais uso das TDIC, os mesmos relatam as redes sociais como o Facebook ${ }^{\circledR}$, Instagram $^{\circledR}$, SnapChat $^{\circledR}$ e WhatsApp $^{\circledR}$.

Assim, além do ambiente virtual de ensino e aprendizagem Moodle, adotou-se o uso de um grupo fechado no Facebook ${ }^{\circledR}$ para compartilhar materiais acerca da disciplina e trocar experiências e informações. Ao final de cada semana de aulas, eram postados para os estudantes materiais complementares como vídeos, simulações, animações, slides, mapas conceituais, histórias em quadrinhos e recursos digitais que estimulassem os estudantes a refletir sobre os conteúdos e testar seus conhecimentos. Alguns materiais eram produzidos pelos próprios estudantes e faziam parte do processo avaliativo. A seguir serão discutidos alguns desses materiais.

A publicação de recursos digitais na rede social, antes das aulas, contribuíram para despertar o interesse dos estudantes pelo conteúdo a ser abordado. Esses materiais foram produzidos na perspectiva de resolução de problemas, como se pode ver na Figura 1, e requeriam dos estudantes uma postura mais ativa no processo de aprendizagem.

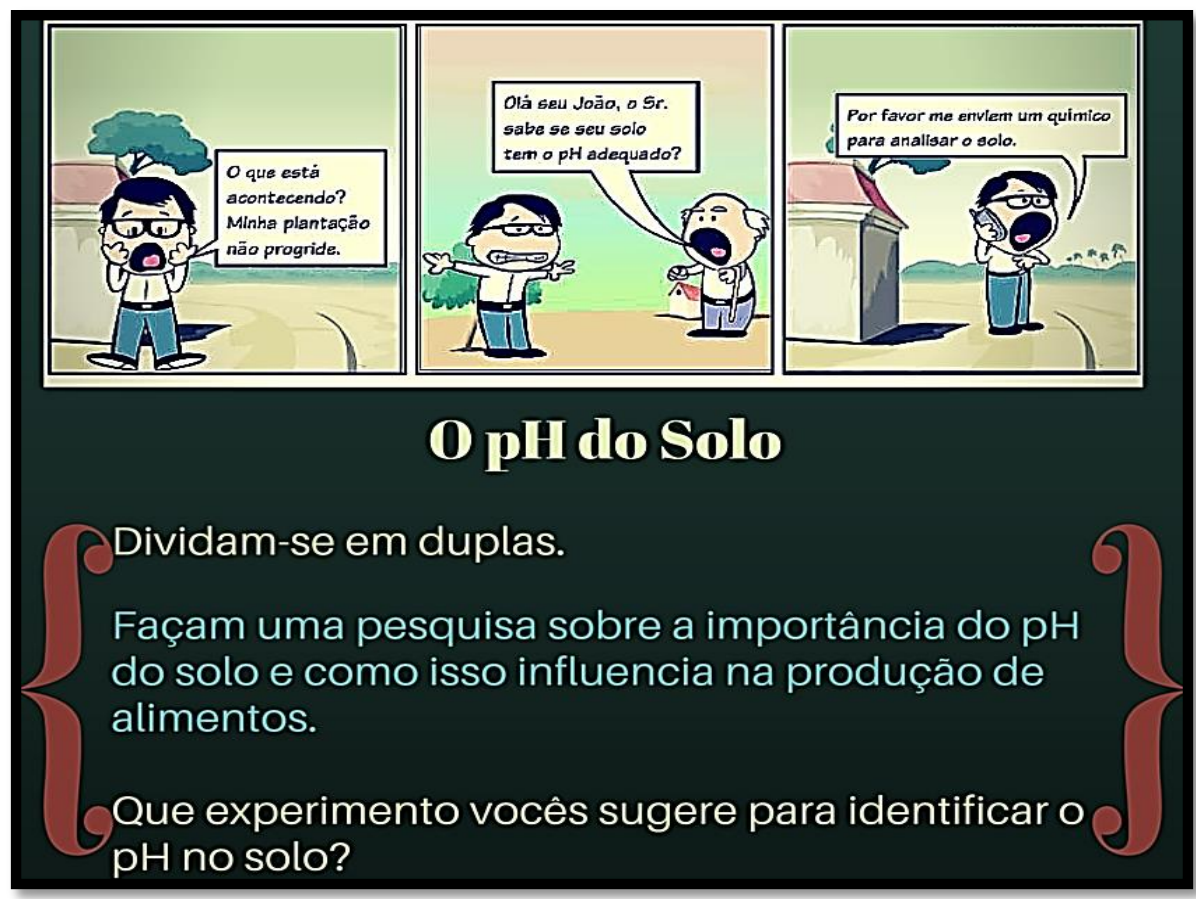

Figura 1 - Affordance sobre o $\mathrm{pH}$ dos solos desenvolvido para propor um problema para os estudantes

O uso desses recursos repercutiu numa participação ativa dos estudantes durante as aulas práticas, visto que os mesmos possuíam argumentos para discutir as possibilidades de análise, conforme suas pesquisas. Esse dado é similar aos obtidos por Felcher, Pinto, e Ferreira (2017). Desde a inserção desses materiais problematizadores, observou-se uma mudança de postura dos estudantes, que se tornaram mais interessados e participativos. Assim, aliar os recursos educacionais a resolução de problemas e as atividades experimentais contribuem efetivamente para a construção do conhecimento. Por outro lado, ao que se refere a rede social, observou-se que o uso da mesma desperta 
mais a atenção dos estudantes que o ambiente virtual Moodle, o que era de se esperar de uma tecnologia ubíqua que perpassa o cotidiano dos estudantes.

Para potencializar a compreensão de fenômenos químicos em nível microscópico buscou-se no decorrer da disciplina fornecer subsídios para os estudantes compreenderem os conteúdos que requeriam esse nível de abstração. A figura 2 apresenta um exemplo de objeto de aprendizagem disponibilizado. O recurso consiste numa simulação de uma titulação entre um ácido e uma base forte, sendo possível acompanhar no decorrer da reação o comportamento do $\mathrm{pH}$ do meio, assim como o que ocorre em nível molecular.

O recurso educacional auxilia os estudantes a compreender o conteúdo teórico e visualizar em nível microscópico àquilo que realizam em laboratório presencial. Assim, a cada adição de hidróxido de sódio $(\mathrm{NaOH})$, eles observam a mudança do $\mathrm{pH}$ decorrente da reação entre este o ácido clorídrico $(\mathrm{HCl})$, formando água $\left(\mathrm{H}_{2} \mathrm{O}\right)$ e o cloreto de sódio $(\mathrm{NaCl})$, o qual sendo um sal se dissocia formando as espécies iônicas $\mathrm{Na}^{+}{ }_{(\text {aq) }}$ e $\mathrm{Cl}^{-}{ }_{(\mathrm{aq})}$. $\mathrm{O}$ recurso permite ainda, em uma outra janela, que os mesmos realizem os cálculos referentes à análise química, podendo assim testar seus conhecimentos.

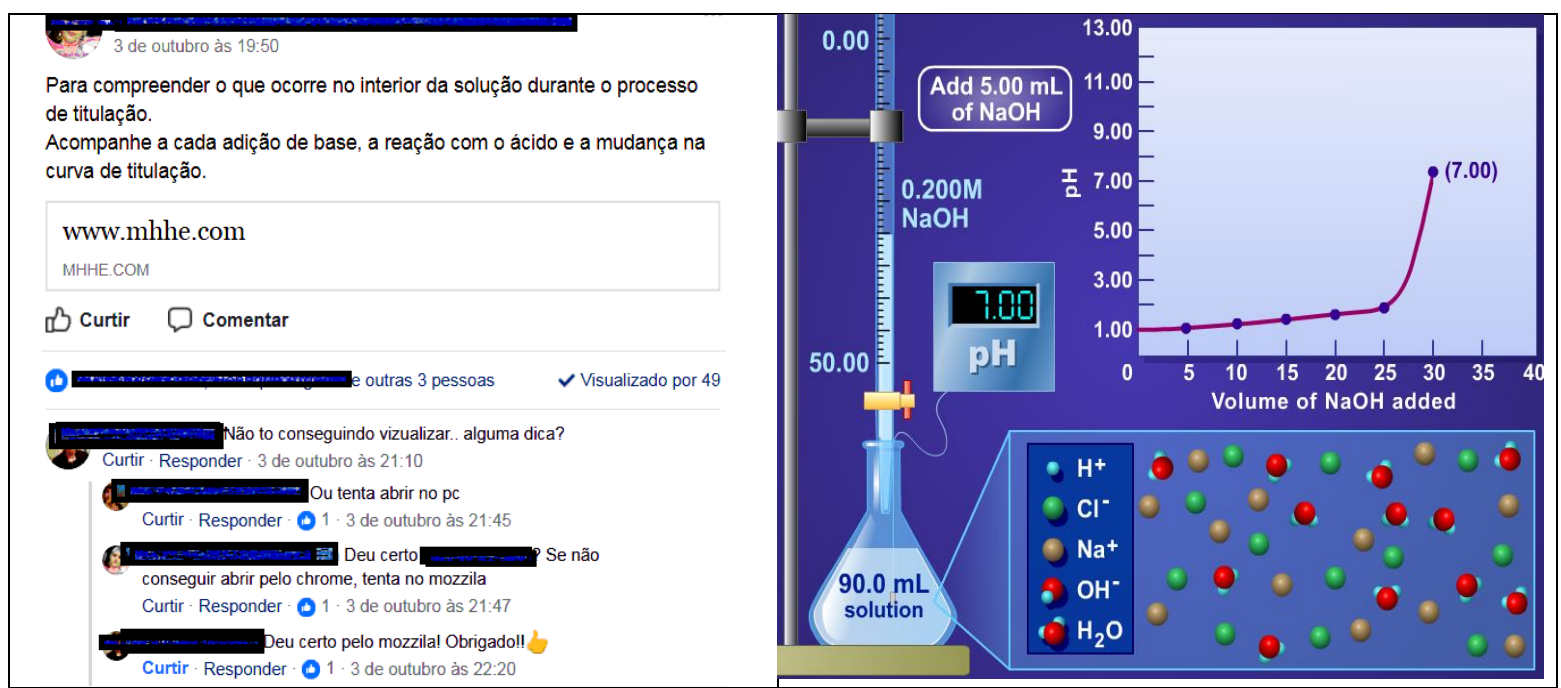

Figura 2 - Simulação de um processo de titulação entre ácido forte e base forte.

Fonte: http://www.mhhe.com/physsci/chemistry/animations/chang_7e_esp/crm3s5_5.swf

Pela figura 2 pode-se observar que dos 56 estudantes dessa turma (2017/b), 49 visualizaram a postagem, sendo que aqueles que não conseguiram abrir o recurso entraram em contato solicitando auxílio, o que demonstra que os mesmos realmente interagem com os recursos educacionais propostos, diferente do que se observava anteriormente ao uso das redes sociais. De acordo com Alencar, Moura e Bittencourt (2013), inserir mídias sociais, no caso o Facebook $^{\circledR}$, no contexto educacional é uma tarefa fácil, já que os nativos digitais estão habituados a utilizá-las no seu cotidiano.

Outrossim, como afirmam Túñez López e Garcia (2012), os recursos educacionais compartilhados ficam disponíveis para os estudantes permanentemente, sendo que os mesmos podem utilizá-los quantas vezes for necessário para compreenderem os sistemas. No entanto, surge como desafio ao uso da rede social a organização dos recursos no ambiente, visto que após alguns dias, os estudantes já não encontravam o recurso com a mesma facilidade da semana inicial na qual o mesmo era fixado no topo da rede. Nesse sentido, os ambientes virtuais de ensino aprendizagem, como o Moodle, apresentam vantagem no que se refere a organização dos materiais, em uma sequência lógica que obedece aos critérios elencados pelo professor responsável. 
O Facebook ${ }^{\circledR}$ apresenta uma ferramenta interessante - Enquete - que pode ser utilizada no processo de ensino e aprendizagem para verificar a opinião dos estudantes sobre um determinado assunto. Assim, no intuito de avaliar a opinião dos estudantes em relação ao potencial dos materiais extras postados na rede social para a aprendizagem, criou-se uma enquete, como mostra a figura 3. Pela figura pode-se observar que embora a enquete não tenha sido respondida por todos os estudantes, a maior parte dos respondentes concorda totalmente que o uso desses recursos contribuem para seu aprendizado. Pelos resultados nenhum estudante discorda desse fato, enquanto que dois estudantes apontam que é indiferente. Assim, como afirma Juliani et al (2012), as redes sociais permitem aos professores terem um feedback de suas aulas e dessa forma dinamizar o processo de ensino e aprendizagem, provendo materiais diversificados que possibilitam modificar a forma de ensinar e aprender.

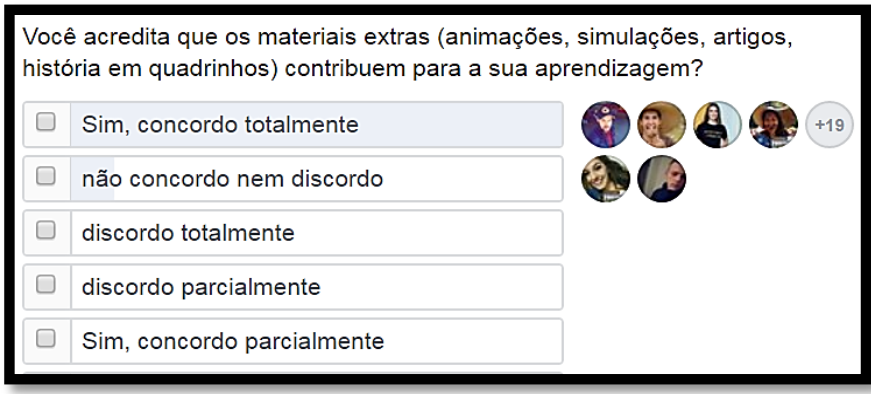

Figura 3 - Enquete disponibilizada na rede social em uma das turmas para avaliar a opinião dos estudantes sobre o uso de recursos das TDIC.

Apesar do resultado representar a opinião de apenas uma das turmas, o questionamentos foi feito às demais turmas e os resultados obtidos em todas elas é similar à essa amostra, o que demonstra que os estudantes acreditam na potencialidade de recursos das tecnologias como elemento de mediação do aprendizado. Isso comprova o que apontam da Silva e Pinto (2009), de que a nova geração possui fluência nos recursos da web 2.0 e fazem uso desses para compreender os conteúdos teóricos, muitas vezes abordados de forma desinteressante nas aulas presenciais.

Os resultados aqui obtidos são concordantes com o que relatam Possolli, do Nascimento e da Silva (2015, p.8), que os entrevistados em sua pesquisa, apontam que uma das formas de se usar o Facebook ${ }^{\circledR}$ pedagogicamente seria a "postagem de conteúdos complementares ao trabalho de sala de aula", seguida da criação de grupos na rede social para discussão dos conteúdos. Isso é corroborado por Iahnke, et al., (2014, p.9) que avaliam "o compartilhamento do conhecimento, a partir das redes sociais, seja maior do que numa aula tradicional, pois um aumento da colaboração entre os discentes é esperado ao empregar-se o Facebook ${ }^{\circledR}$ como um ambiente pessoal de aprendizagem".

Moran (2015) afirma que o uso das redes sociais permite a inovação do fazer docente, permitindo modificar a dinâmica das aulas e propor situações de aprendizagem nas quais os estudantes sejam protagonistas. Assim, além da disponibilização de recursos educacionais e a promoção de debates no grupo fechado da rede social, os estudantes eram instigados a produzir materiais instrucionais sobre os conteúdos abordados em sala de aula, como vídeos, mapas conceituais e infográficos. Esses materiais eram compartilhados no grupo e fomentavam discussões e questionamentos. As figuras 4 a 6 apresentam alguns desses materiais produzidos pelos estudantes. 


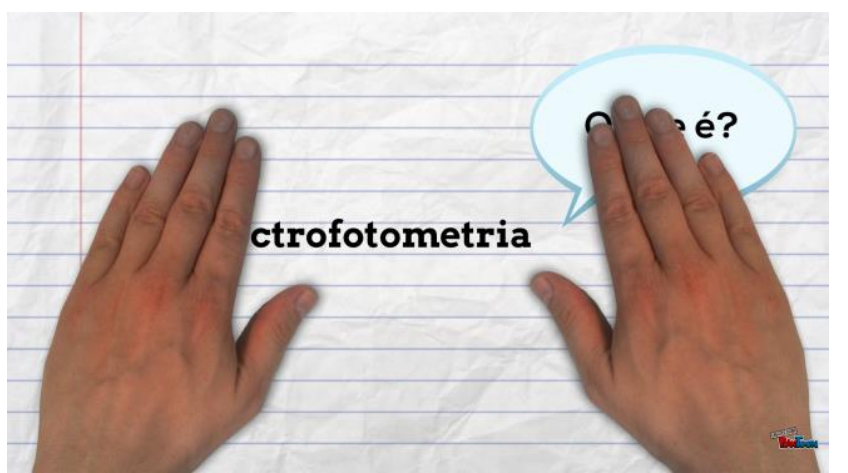

Figura 4 - Exemplo de vídeo produzido pelos estudantes da disciplina Fonte: https://www.powtoon.com/c/cr9dU2m5aVe/2/m

Os vídeos elaborados pelos estudantes eram muito criativos, sendo que não houve relatos de dificuldades em criá-los. Esses vídeos eram postados no grupo fechado e a cada postagem os estudantes teciam comentários sobre as produções, não só sobre os conteúdos abordados como também como elogios e contribuições aos trabalhos dos colegas. É interessante relatar que após a primeira postagem, outros estudantes se sentiram motivados a realizar a atividade e, imbuídos de um espírito competitivo saudável, superar em criatividade os vídeos dos colegas. Essa disputa, sob o ponto de vista das autoras é sadia, à medida que promove um desafio a ser superado e instiga os estudantes a darem vazão ao seu potencial criativo.

Tornar o sujeito ativo do processo de aprendizagem é um dos desafios da sociedade da informação, pois apoiado nas Teorias da Carga Cognitiva (SWELLER, 2004), as aulas meramente expositivas, em sua maioria, não provém estímulos suficientes para que o processamento dos sinais (pictóricos e auditivos) sejam processados pela memória de trabalho para assim ser organizados, hierarquizados e conectados a outros conhecimentos já existentes. Ou seja, ao propormos atividades de estudo que proporcionem aos estudantes serem protagonistas do processo de ensino e aprendizagem, estes conseguem aprender de uma forma mais efetiva, estabelecendo conexões e hierarquizações que constituem os esquemas da memória de longo prazo. No entanto, atividades que remetem à cópia ou a memorização, são facilmente esquecidas. Assim, ao usar a rede social como suporte ao processo de aprendizagem, é necessário planejar recursos e atividades de estudo que primem pela experiência no fazer.

Segundo Basso et al., (2013), o Facebook ${ }^{\circledR}$ tem grande potencial para o ensino e aprendizagem, mas apresenta como um dos maiores desafios a mudança de paradigmas, pois na rede social o estudante deve não apenas ser parte integrante, mas atuante, demonstrando-se mais autônomo e responsável pela construção do processo de aprendizagem. Portanto, cabe ao professor planejar o uso da rede e as atividades que conduzam o estudante à construção de saberes na coletividade.

Assim, foi proposta a produção dos mapas conceituais, inicialmente os estudantes mostraram-se pouco entusiasmados em fazê-lo, pois a grande maioria nunca havia produzido um mapa. No entanto, todos acharam as ferramentas de produção muito simples e surpreenderam com os materiais produzidos, como é possível observar na Figura 5.

A maioria dos mapas conceituais produzidos pelos estudantes eram bastante ricos e demonstram que os mesmos compreendem o assunto, pois conseguem estruturá-lo de forma hierárquica, relacionando os conceitos adequadamente e ainda, fornecendo exemplos de aplicação em sua área de formação. O conteúdo produzido por meio dos mapas foi posteriormente requerido em uma das avaliações formais da disciplina. Durante a avaliação vários estudantes solicitaram se poderiam responder aos questionamentos por 
meio do mapa conceitual, pois assim, conseguiam expressar melhor o que haviam aprendido.

Esse resultado demonstra que ao propor atividades de estudo que requerem não apenas a reprodução de textos, mas que exploram o potencial criativo dos sujeitos, proporciona-se o desenvolvimento psíquico e intelectual dos mesmos, como afirmam Alberti e Bastos (2008, p.246):

[...] a escolha dos conteúdos a serem trabalhados e a forma como eles serão ensinados, será decisiva no desenvolvimento qualitativo-escolar dos alunos. Portanto, precisamos nos preocupar com a organização das atividades de estudo a serem desenvolvidas com os mesmos [...]

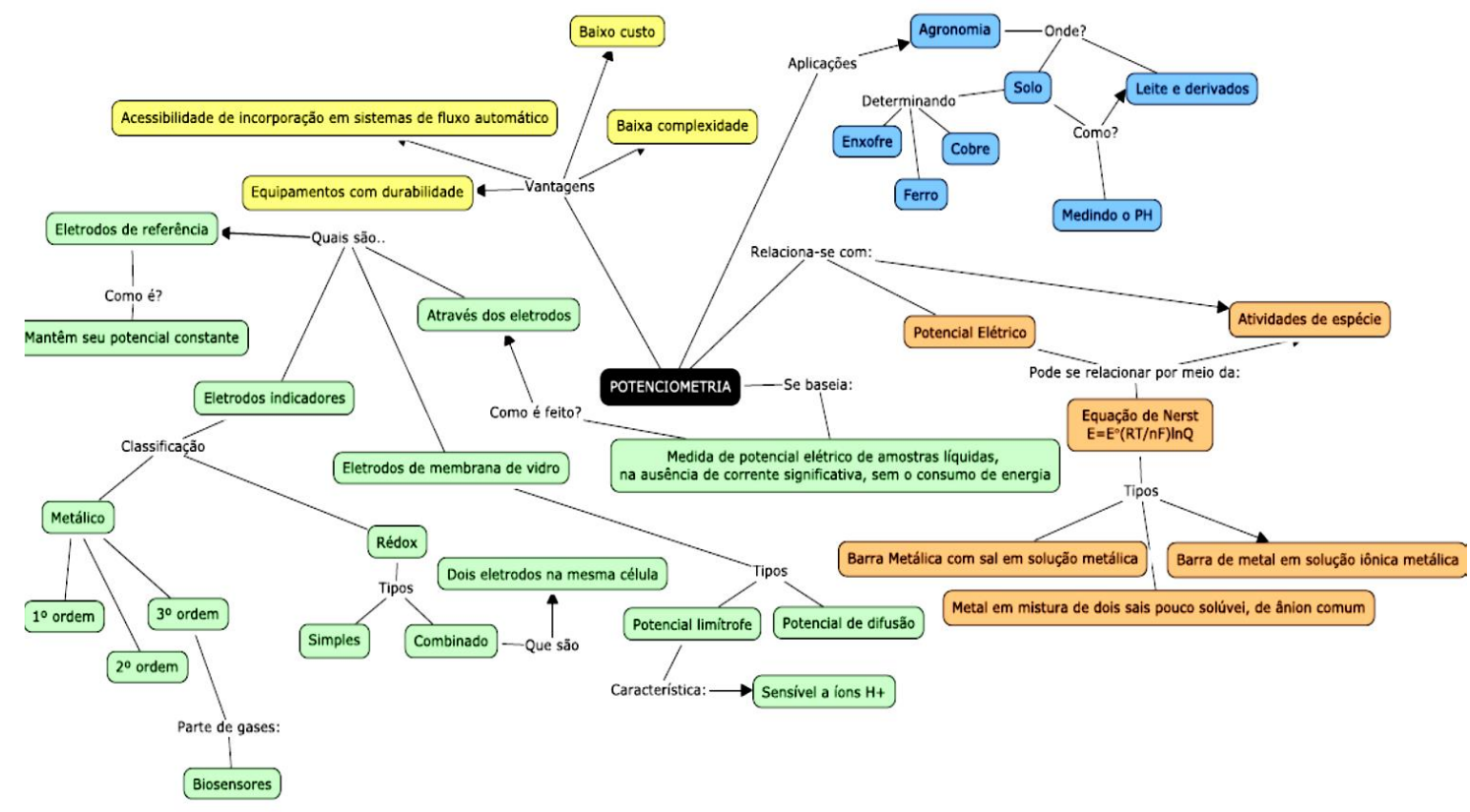

Figura 5 - Exemplo de mapa conceitual produzido pelos estudantes da disciplina

Dentro de uma perspectiva espiralada similar ao que sugere a pesquisa-ação, ao observar as primeiras turmas e nos deparar com suas dificuldades, buscou-se planejar novas atividades de estudo que possibilitassem aos estudantes minimizar os desafios encontrados no processo de aprendizagem. Assim, foi proposto aos estudantes a produção de infográficos que abordassem o princípio de Le Chatelier. A atividade deveria ser feita em duplas e o material produzido disponibilizado na rede social para discussão. Disponibilizou-se na rede social um exemplo de infográfico relacionado a química das cores das folhas do outono e indicou-se alguns softwares onde os infográficos poderiam ser construídos, como o Canva Design (https://www.canva.com/) e o Easilly (https://www.easel.ly/), bem como vídeos tutoriais dos mesmos.

É interessante observar na figura 7, que alguns grupos já conseguem transpor o saber sábio (preceitos científicos) ao saber a ser aprendido (prática). Dessa forma ao tornar o sujeito partícipe do processo de ensino e aprendizagem, não apenas o professor, mas o estudante realiza a transposição de saberes, o que contribui para a potencialização do aprendizado. Nesse contexto, o uso das redes sociais facilita o compartilhamento de ideias e promove a interação dos estudantes num processo de aprendizagem coletiva.

Os dados obtidos corroboram os de Patrício e Gonçalves (2010), que afirmam que as redes sociais podem ser exploradas como um recurso pedagógico inovador para promover a interação, a colaboração e competências tecnológicas no ensino superior. 

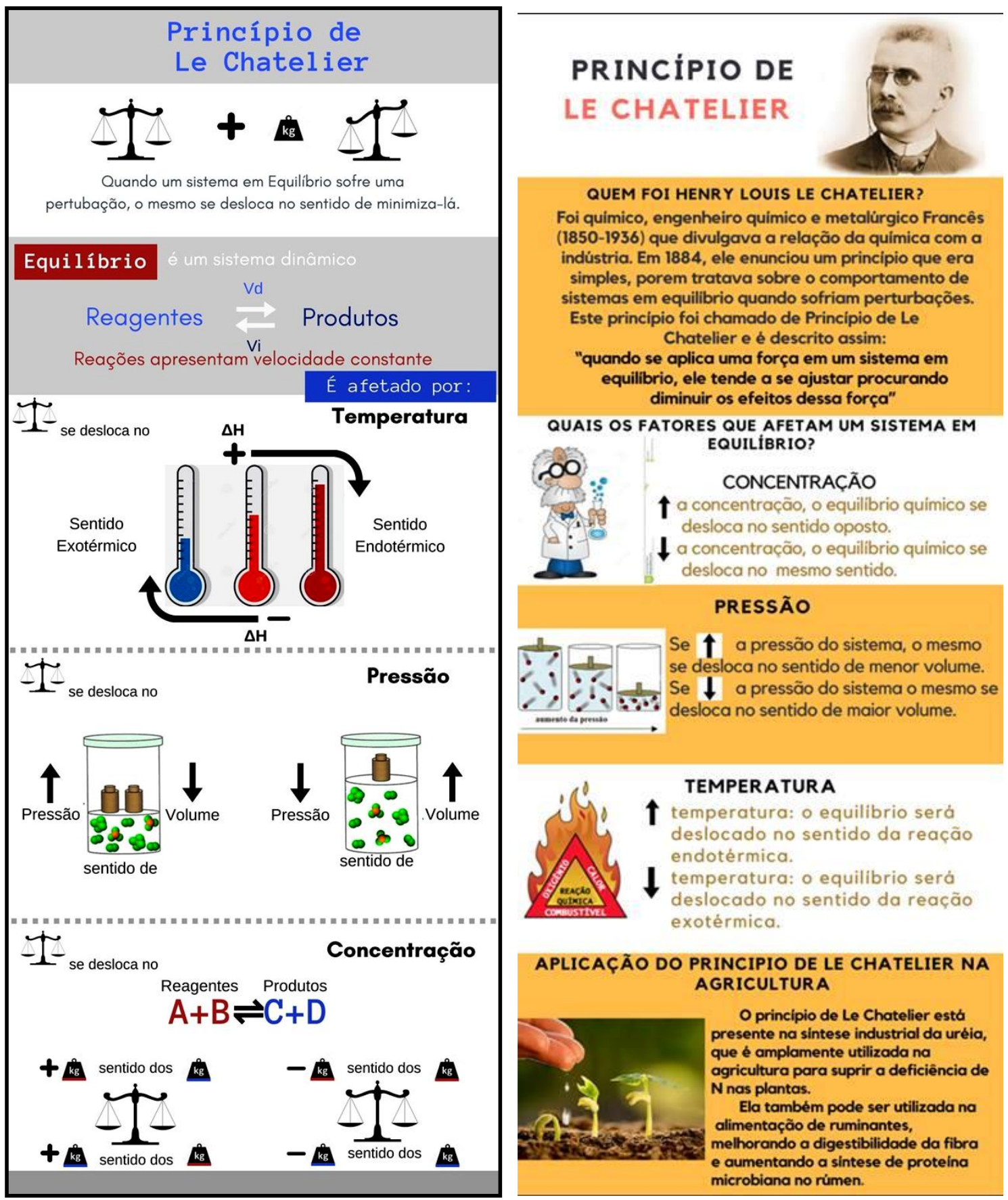

Figura 6 - Exemplos de infográficos produzido pelos estudantes da disciplina

Dentre os desafios encontrados no decorrer do processo, aponta-se a necessidade de mudança de postura do professor, que deixa de ser mero transmissor do conhecimento para ocupar o papel de mediador da aprendizagem. Além disso, aponta-se que o uso da rede social requer um monitoramento constante e a produção/escolha de recursos educacionais que possam contribuir para despertar o interesse dos estudantes e potencializar o aprendizado. Como afirmam Felcher, Pinto e Ferreira (2017, p.254):

Enfatiza-se a necessidade e a relevância do papel do professor nesse espaço virtual, pois as tecnologias por si só não se bastam. O professor é singular na escolha das propostas, na mediação e no incentivo para que os alunos possam interagir, saindo da condição de passivo. 
Nossos resultados confirmam o que relatam Possolli, do Nascimento e da Silva (2015), de que o Facebook $\circledR$ apresenta grande potencialidade para promover a interação social e dar nova dimensão à sala de aula no ensino superior, ampliando os espaços de troca e construção de saberes, bem como tornando os estudantes partícipes do processo de ensino e aprendizagem e não apenas meros expectadores. Ressalta-se, no entanto, que uso da rede social, por si só, não se configura uma atitude inovadora, se não houver planejamento e monitoramento pelo docente, que promove o debate e a construção de saberes de forma conjunta, tornando o estudante protagonista do seu aprendizado.

\section{Considerações Finais}

As observações decorrentes dos 2 anos e meio do uso das redes sociais como ambiente de aprendizagem corroboram as afirmações de Da Silva e Pinto (2015), de que essa geração tem fluência nos recursos da tecnologia pois não apenas navegam por estes, mas produzem a partir desses, recursos materiais educacionais que facilitam o seu aprendizado.

As atividades de estudo, desde que planejadas com objetivos bem claros, possibilitam a construção de saberes de forma autônoma, desenvolvendo a criatividade e a criticidade, características tão desejadas nos dias atuais. Além disso, atividades com potencial criativo minimizam o tão criticado CTRL C + CTRL V, pois não remetem à mera cópia, mas sim à autenticidade e autoria, o que impacta na qualidade do aprendizado.

Quando arguidos em sala de aula quanto ao uso das redes sociais, os estudantes afirmam que esse espaço de aprendizagem complementa a sala de aula e os impulsiona a buscar mais informações sobre o assunto. Segundo os estudantes ao receberem notificações sobre as novas publicações no grupo, os mesmos eram impulsionados a visualizá-las. Assim, podemos afirmar que as redes sociais podem contribuir para a melhoria do aprendizado no ensino superior, desde que sejam monitoradas e estabelecidas algumas regras de uso, como por exemplo, só permitir postagens e discussões acerca dos contextos trabalhados na disciplina.

Pautados nos resultados obtidos ao longo desse estudo é possível afirmar que as redes sociais produzem saberes na coletividade e podem ser uma excelente alternativa para promover a discussão de conteúdos no ensino superior, pois observa-se que os estudantes partilham e interagem uns com os outros impulsionando os processos de construção de saberes. No entanto, para o sucesso do uso da rede, o professor deve estar aberto para as mudanças de paradigmas que aqui se apresentam, sendo não mais o detentor do saber mas o mediador do processo de ensino e aprendizagem.

\section{Bibliografia}

ALBERTI, T.F.; DE BASTOS, F. da P.. A Teoria da Atividade como orientação psicopedagógica na implementação de atividades de estudo em Ambientes Virtuais. Ciências \& Cognição, v. 13, n. 2, p. 243-257, 2008.

ALENCAR, G.A.; MOURA, M.R.; BITENCOURT, R.B.. Facebook como Plataforma de Ensino/Aprendizagem: o que dizem os Professores e Alunos do IFSertão-PE. Educação, Formação \& Tecnologias, v. 6, n. 1, p. 86-93, 2013.

BASSO, M. et al. Redes sociais: espaço de aprendizagem digital cooperativo. Conjectura: filosofia e Educação, v.18,n.1, p.135 - 149, 2013. 
BOSCH, T.E. Using online social networking for teaching and learning: Facebook use at the University of Cape Town. South African Journal for Communication Theory and Research v.35, n.2, p. 185-200, 2009.

DA SILVA, J. F.; PINTO, A. C. Geração C: Conectados em novos modelos de aprendizagem. In: VIII Brazilian Symposium on Games and Digital Entertainment Rio de Janeiro, RJ-Brazil. 2009.

ELLENSOHN, R.M.; BARIN, C.S. Redes Sociais como ambiente de comunicação e aprendizado. Revista Tecnologia na Educação, n. 14, p. 1-11, 2016.

FELCHER, C.D.O.; PINTO, A.C.M.; FERREIRA, A.L.A.. O uso do Facebook como ambiente virtual de aprendizagem para o ensino dos números racionais. Revista Paranaense de Educação Matemática, v.6, n.10, p. 246-271, 2017.

GIL, A. C. Como elaborar projetos de pesquisa. 5. ed. São Paulo: Atlas, 184p. 2010.

IAHNKE, S.L.P; BOTELHO, S.S.C; FERREIRA, A.L.. COLMEIAS: A Integração das Aprendizagens Móvel e Colaborativa para Potencializar a Aprendizagem Significativa. Renote. v 12, n. 2, 2014

IRWIN, C.; BALL, L.; DESBROW, B.; LEVERITT, M.. Students' perceptions of using Facebook as an interactive learning resource at university. Australasian Journal of Educational Technology, v.28, n.7, p. 1221-1232, 2012.

JULIANI, D. P., JULIANI, J. P., DE SOUZA, J. A., DE BETTIO, R. W.. Utilização das redes sociais na educação: guia para o uso do Facebook em uma instituição de ensino superior. Renote, v. 10, n. 3, 2012.

MORAN, J. Mudando a educação com metodologias ativas. Coleção Mídias Contemporâneas. Convergências Midiáticas, Educação e Cidadania: aproximações jovens, v. 2, p. 15-33, 2015.

PATRÍCIO, M.R.; GONÇALVES, V. Utilização educativa do facebook no ensino superior. In: I International Conference learning and teaching in higher education. Universidade de Évora, 2010.

POSSOLlI, G.E.; DO NASCIMENTO, G. L.; DA SILVA, J. O. M.. A Utilização do Facebook no Contexto Acadêmico: o Perfil de Utilização e as Contribuições Pedagógicas e para Educação em Saúde. Renote, v. 13, n. 1, 2015.

RACTHAM, P; FIRPO, D. Using social networking technology to enhance learning in higher education: A case study using Facebook. In: System Sciences (HICSS), 2011 44th Hawaii International Conference on. IEEE, 2011. p. 1-10.

SWELLER, J.. Instructional design consequences of an analogy between evolution by natural selection and human cognitive architecture. Instructional science, v. 32, n. 1-2, p. 9-31, 2004.

TÚÑEZ LÓPEZ, M.; SIXTO GARCÍA, J.. Las redes sociales como entorno docente: análisis del uso de Facebook en la docencia universitaria. Pixel-Bit. Revista de Medios y Educación, n. 41, 2012. 